\title{
Distilling the Essence of the McKinsey Way: The Problem-Solving Cycle
}

\begin{abstract}
Consulting projects where students are tasked to propose solutions to a client issue are a common feature in many business courses. Whether scenario-based or dealing with real clients, students engaged in consulting tasks tend to focus on solution development without giving due consideration to the underlying process by which they derive their solutions. Drawing on consulting practitioner approaches, this article presents a translation of the McKinsey approach as a six-stage structured problem-solving methodology that can be used to guide students on how to develop solutions in a systematic, logical, and evidence-based way. Prescribing a standardized methodology to students to guide their approach to consulting tasks ensures that they are able define and decompose business problems effectively, and enhances the credibility of their proposed solutions.
\end{abstract}

Keywords: management consulting, problem-solving, methodology, McKinsey approach, work integrated learning 


\section{Distilling the Essence of the McKinsey Way: The Problem-Solving Cycle}

"When you strip away a lot of the high-minded language with which McKinsey dresses up its problem-solving process, it comes down to very careful, high-quality analysis of the components of the problem combined with an aggressive attitude toward fact gathering"

(Rasiel, 1999, p. 4)

For many students, solving business problems as a consultant can be a daunting undertaking. Consulting projects often have fuzzy scope boundaries, whereby students have to work with imperfect information to arrive at well-reasoned solutions to a particular client issue (Hargadon $\&$ Bechky, 2006). Such constraints are not unique to learning tasks in business courses, but realistically characterize real-world projects that management consultants frequently encounter (Block, 2011). Practitioner consultants apply problem-solving methodologies to overcome these constraints in their engagements (Friga, 2009). These methodologies empower consultants to frame, structure, and sequence project activities, in a logical and systematic way, to ensure they find the best possible recommendations to a business problem or opportunity.

This article presents a problem-solving methodology entitled, 'Problem-Solving Cycle' (PSC), that I have used with students working on consulting projects in an undergraduate workintegrated consulting course ${ }^{1}$. This article commences with a discussion of the challenges of teaching consulting, and the value of using a structured problem-solving approach. Following this, this I share some insights on the translation process before providing a step-by-step guide for implementing the PSC. I conclude with some suggestions on how the methodology can be debriefed with students.

\section{Structured Problem-Solving and Student Learning}

Consulting students often have preconceived ideas of what consulting is and ambitions to 
learn 'secret' consulting frameworks and tools. They soon discover that consulting is neither a single technique, nor a mere collection of practices or tools; if anything, consulting is best described as a process (Schein, 1997). The process of how a consultant conducts their work is often just as important, if not more so, than the final solution itself. Presented with a client issue, students' instinctively preempt solutions without thorough consideration of the process used to derive their solutions. However, if a client doesn't trust the underlying problem-solving process used, it is unlikely the client will embrace the solution/s proposed.

In my consulting classes I want to equip students with the process knowledge on how to approach business problems in a logical, systematic, and evidence-based way. I believe it is important to teach students a structured approach to problem solving because: (1) it establishes a path for them to clearly define and decompose problems that leads to well-reasoned solutions; (2) it focuses their time, attention, and effort on issues that are most relevant to the key problem, and (3) adherence to a methodology enhances the credibility of the solution and gives confidence to the client.

\section{The Translation Process: Insights and Suggestions}

Within the consulting literature, variant methodologies exist that vary in their complexity, terminology used, and the number and sequencing of problem-solving stages ${ }^{2}$. The methodology I use in my classes is the 'Problem-Solving Cycle' (PSC), which is a format translation of the McKinsey approach ${ }^{3}$. This translation is based on practitioner texts by Rasiel (1999), Rasiel and Friga (2001), and Friga (2009), and is supplemented by various publicly available resources on the McKinsey approach ${ }^{3}$. Five student-centered criteria were used to guide the translation: (1) applicable, (2) comprehensible, (3) generalizable, (4) experiential, and (5) assessable. Table 1 describes each criterion and presents the underpinning rationale as well as specific examples of 
criterion applications. For instructors considering format translations of practitioner methodologies, Table 1 should serve as a useful guide.

\section{INSERT TABLE 1 ABOUT HERE}

The translation process was an iterative undertaking that occurred over numerous semesters of teaching. In the first semester, I taught the McKinsey approach in its original format and obtained student feedback to identify aspects of the methodology that they found challenging or confusing. Based on this feedback, the translation criteria were inductively developed and guided the translation of the McKinsey approach into the PSC. To ensure fidelity to the McKinsey approach, the PSC was reviewed with two experienced management consultants to verify that key consulting principles were adequately covered in the methodology.

The purpose of translation was to ensure that the methodology was presented in an accessible way for students ${ }^{4}$. Practitioner content is often written and presented without a pedagogical focus; hence the translation process needs to be iterative and responsive to the learning needs of students. Accordingly, during the translation process it is important to obtain feedback from students regarding the usability of the of the methodology. It was also useful engaging practitioners during the translation who were also useful in proposing experiential activities and formative assessment tasks.

\section{Problem Solving Cycle (PSC): An Implementation Guide}

The PSC methodology in Figure 1 can be taught in a single 21/2 to 3 hour class or modularized and covered over a number of classes. As teaching resource, the PSC is targeted at management educators who have some consulting experience and/or teach work-integrated 
learning subjects or use case-based assessments in their courses.

\section{INSERT FIGURE 1 ABOUT HERE}

The PSC begins with the contextual factors surrounding a client's business problem (e.g. Why was the project commissioned? What is the client's desired outcome? How does the project relate to the organization's strategic goals?). This information may be partly ascertained from the client's project brief; however, students should also conduct further background research using secondary sources (e.g. industry databases) to understand the client's industry and operating context. Before meeting with their client, students should also prepare interview schedules comprised of questions designed to solicit information required for stage 1 of the PSC.

\section{Stage 1: Defining the Problem}

In stage 1 students are required to devise a crisp definition of the problem in the form of a single 'big' question that drives all subsequent stages of the methodology. This should be codeveloped with their clients to establish a shared understanding of the scope and nature of the problem. Where possible, the wording of the 'big' question should fulfill the SMART criteria: Specific (S), Measurable (M), Action-oriented (A), Relevant (R) to the key problem, Timebound (T). See Appendix A for a sample learning activity.

\section{Stage 2: Structure Before Data}

Stage 2 entails constructing an issue tree that decomposes the 'big' question into its component parts ${ }^{5}$. The issue tree, as illustrated in Figure 2, is a tool used to disaggregate the problem into core sub-issues that need to be addressed in order to answer the 'big' question. Each sub-issue branch should be mutually exclusive (i.e. should not overlap) and, when taken 
together, the issue tree should be collectively exhaustive (i.e. sub-issues should aggregate to fully answer the key question). This is known as the 'MECE' (pronounced 'me-see') principle.

\section{INSERT FIGURE 2 ABOUT HERE}

A 'big' question can often be decomposed in multiple ways. Students will rarely produce a fully MECE tree on their first attempt and should work collaboratively in teams to iterate and refine their issue trees. Depending on project complexity, this could take anywhere from 15minutes to a couple of hours. The role of the instructor is to identify possible breaches of the MECE principle, and to encourage students to justify their decomposition logic. Learning activities are provided in Appendix B.

\section{Stage 3: Prioritize Issues and Plan}

In stage 3, students prioritize identified issues (i.e. tree branches) to determine focal drivers of the problem. Prioritization is based on the Pareto principle (i.e. 80/20 rule), whereby students assess which issues are most important in answering the 'big' question (Rasiel, 1994). The premise is that $\sim 80 \%$ of the problem can be accounted for by $\sim 20 \%$ of the issues identified. Prioritization can be based on simple analytical techniques, such as simple ratios, benchmarking, sensitivity analysis, and/or qualitative stakeholder input (Baiij, 2014). A more systematic approach includes determining and applying prioritization criteria to eliminate issues. For instance, using two decision criteria, students can plot issues on a two-by-two matrix (e.g. two axis of a matrix feature 'urgency' and 'impact'). Once issues have been prioritized, students should prepare a data collection plan (see Appendix C) to ensure data is collected in a planned and deliberate fashion. 


\section{Stage 4: Analyze to Derive Findings}

Analysis aims to reveal relationships and patterns in the data which can be achieved with various analytical techniques. The type of analysis depends on what answers students are trying to ascertain, and the kind of data that has been collected (e.g. primary versus secondary, qualitative versus quantitative). For quantitative datasets, various charts and graphs can be used to uncover patterns, aided by software such as Excel, Tableu, Minitab, and SPSS. For qualitative datasets, students can conduct thematic analyses of textual data or use data visualization tools, such as word clouds. Students should ensure that the analytical technique employed is aligned with the issue tree and 'big' question (See Appendix D). In my consulting course, most enrolled students have already learnt various analysis frameworks and techniques in other courses which they incorporate into stage 4 .

\section{Stage 5: Synthesize Findings into Insights}

Synthesis refers to the art of storytelling and is regarded as the most challenging element of the methodology. A common source of client frustration is when student consultants provide a summary of facts, rather than offering considered insights inferred from the facts. As shown in

Figure 3, synthesis requires students to translate facts into insights and to craft a threading narrative that concisely connects insights to the 'big' question. Mastering the art of synthesis requires students to iteratively draft their writing and to receive ongoing feedback from instructors ${ }^{6}$.

\section{INSERT FIGURE 3 ABOUT HERE}




\section{Stage 6: Propose Solutions}

In the final stage, students develop solutions that answer the key question. The quality of solutions hinges on whether students have correctly identified the root drivers/causes in stage two, and their ability to think logically and innovatively. As Baiij (2014) proposes, solutions can be developed using three approaches: (1) exploit collective experience (i.e. draw on tacit knowledge from similar projects), (2) exploit public domain knowledge (e.g. publicly available frameworks, comparator case studies), and (3) explore new solutions (e.g. blue-sky thinking, structured brainstorming). Beyond just describing the solutions, students should also be asked to propose implementation plans for their clients.

\section{Debriefing the Exercise}

Although the PSC appears in a linear sequence, students should be advised that its application in practice is iterative and requires moving back and forth between the various stages. Specific instruction for debriefing each stage of the PSC are included in the corresponding appendices. In teaching the PSC, the role of the instructor is to encourage persistence amongst students and to facilitate students' experimentation with the methodology (particularly in stage 2). Practitioners are able to apply the methodology efficiently because they possess a repertoire of project experience to identify and eliminate issues quickly (Liedtka, 2006). For students lacking this experience, the only way to learn the methodology and understand its value is by practicing and persisting with its application. As one of my students noted in their feedback: "Although following the consulting methodology was very annoying and tedious, it did help our team formulate the project in a better way and forced us to learn the consulting process effectively". As a debriefing exercise, I also invite professional consultants from top consulting firms to present case studies on how they've approached problem-solving, 
all of which closely resemble the PSC. Students have found this debriefing exercise useful in reinforcing their understanding of the practical value of structured problem-solving approaches.

\section{Conclusion}

Consulting is an applied discipline and students enrolled in consulting often expect to learn the trade-skills of the profession. However, practitioner insights on consulting practice are often disseminated in public materials and popular books that need to be translated for student audiences. Drawing on the consulting practice literature, this article has demonstrated how the McKinsey approach has been translated into the PSC to guide students in learning structured problem-solving which is a fundamental skill in consulting. Instructors who teaching consulting may look to the practitioner literature and translate applied practices to the classroom to supplement or enhance their current courses to provide students with more authentic learning experiences and equip them with employment-ready skills. 


\section{APPENDIX A: Activity on writing a 'big' question}

This basic activity gives students an opportunity to practice writing a 'big' question that fulfills the SMART criteria. Get students to work in small groups of 3-4, and allocate about 10 minutes to phrase their 'big' question and 5 minutes for debriefing.

\section{$\underline{\text { Instruction }}$}

1. Present the following scenario to students to commence the activity:

"Kaltex - a large multinational oil refinery-is seeking to improve its profitability by $\$ 40$ million per year as part of its 5-year strategic plan. Although the company's revenue has increased year on year, the company's overall profitability has remained relatively stagnant. The company's management team has enlisted your consulting firm to assist them in achieving their financial targets".

2. Ask students to prepare a 'big' question based on the contextual facts provided. Students should be asked to write down their initial question and constantly refine it to fit the SMART criteria. If appropriate, student teams can present their question to the rest of the class, and the instructor can facilitate peer critiques.

\section{Debriefing}

There will be variations in the way students have phrased their questions. Some examples of poorly worded questions written by students are presented below:

- "Kaltex is suffering from poor profitability despite strong revenues" (Critique: This is a statement of fact and has not been phrased as a question).

- "Should Kaltex improve its deteriorating position" (Critique: This question is not disputable). 
- "Can Kaltex be managed differently to increase profitability" (Critique: This question is too general).

Based on the contextual facts, astute students would identify that the profitability problem is the result of a cost issue rather than a revenue issue. Thus, to improve profitability, the focus of the 'big' question should be on how to reduce the company's cost base. An example of a good 'big' question that fulfills the SMART criteria is:

"What opportunities exist for Kaltex to improve profitability by $\$ 40$ million per year through overhead rationalization, operational improvements, or restricting non-core assets?" 


\section{APPENDIX B: Creating Issue Trees}

Practice and exposure are the best ways for students to learn how to create issue trees. It is one of the more challenging stages in the methodology for students, and it is important that they have opportunities to experiment with the technique. To train students, I first introduce them to the MECE principle by reviewing Figure 2. Before asking students to use MECE on their project/case problems, I have found it useful to get students to first apply the principle to simple problems so they understand how the technique can be applied to broad range of problems. Exercise 1 and 2 below are quick and simple activities designed to familiarize students with the technique. For both exercises, it is helpful for students to work in small groups and to draw their issue trees on whiteboards or butchers paper.

Example/Exercise 1-Reducing monthly expenditure

In this exercise, students are asked to apply an issue tree to structure a problem of reducing personal expenditure. To implement this activity:

1. Break the class up into groups of 3-4 and allocate 10 minutes for all groups to prepare an initial issue tree. All groups are assigned the following problem:

2. "Your brother is in his final semester of his tertiary studies and he is planning to celebrate the completion of his degree at the end of the year by going on an overseas trip. However, in order to afford the trip, he realizes that he needs to reduce his monthly expenditures and has turned to you for some advice."

How can your brother reduce his expenditures each month? Use an issue tree to break the problem down systematically.

3. Debrief the activity by highlighting the multiple ways to deconstruct a problem. The left tree, in Figure B-1, is a typical student response which is not MECE (e.g. the first and second 
branch overlap with the fifth branch, and the fourth branch is not relevant to the key question). Highlight the MECE breaches to students so they understand where they've gone wrong. Instructors can present students with an exemplar MECE tree, as shown in Figure B1.

\section{INSERT FIGURE B-1 ABOUT HERE}

Example/Exercise 2 - Improving Profitability

In this exercise, students are asked to apply an issue tree to structure a profit problem. Unlike the preceding exercise, profit problems have a single correct issue tree because they are based on an equation (i.e. Profit $=($ Unit Price $x$ Quantity Sold $)-($ Fixed cost + Variable Cost $)$. To implement the activity:

1. Break the class up into groups of 3-4 and allocate 10 minutes for all groups to prepare an initial issue tree. All groups are assigned the following problem:

"CrashStar - an automobile dealership-is experiencing a decline in profits.

The owner is interested in understanding why profitability is declining."

Develop an issue tree to identify the factors behind the decline of profit at CrashStar.

2. Debrief the activity by introducing the profit equation and state that, logically, there are only two reasons CrashStar's profit is declining: (a) declining revenue, or (b) increasing costs. The instructor should then draw up the issue tree shown in Figure B-2.

INSERT FIGURE B-2 ABOUT HERE 


\section{APPENDIX C: Preparing a Data Collection Plan}

After students have created an issue tree and prioritized the issues, they should prepare a data collection plan. The data collection plan should be based on priority issues that are clearly linked back to the 'big' question. The purpose of the data collection plan is to ensure that students do not 'boil the ocean' (Rasiel, 1999); that is, not collect unnecessary data that does not link back to their 'big' question, and show that there is clear intent for why they're collecting data. Further, in the absence of a data collection plan, I have found that students tend to: (1) privilege primary data over secondary data, and/or (2) collect a huge amount of primary data they will not use. A data collection plan ensures that students uses secondary data when it's appropriate and available rather than unnecessarily collecting and analyzing their own primary data. In many instances, students may complete entire projects using desk research. Where primary data is collected, the data collection plan ensures that clients, who have busy schedules, are only pulling data that will be used by the students. Figure C-1 show how to translate the issue tree into a data collection plan.

INSERT FIGURE C-1 ABOUT HERE 


\section{APPENDIX D: Analytical Approaches, Tools, and Techniques}

The focus of this article is on the overarching methodology of problem solving rather than specific applications of analytical tools and techniques. The type of analysis required for a given project is highly context-specific. Students are required to make reasoned judgments on the appropriateness of analytical approaches and its relevance to the 'big' question. Where appropriate, instructors may find it useful to provide students with a list of software vendors who provide trial versions of computer-aided analysis and data visualization tools such as Tableau (https://www.tableau.com) and Minitab (http://www.minitab.com). However, not all projects will require such software.

Table 2 provides a snapshot of consulting projects where the PSC has been applied; it does not exhaustively capture all sub-issues, data sources, or analytical techniques. Table 2 highlights that the analytical technique employed depends largely on the client problem being addressed and the type of data that is collected. There is no single analytical technique or framework that is relevant for all projects. Depending on the nature of the project and client preferences, students may draw entirely on secondary data when completing their projects (e.g. Bank Y and Firm Z). 


\section{Declaration of Conflicting Interests}

The author(s) declared no potential conflicts of interest with respect to the research, authorship, and/or publication of this article.

\section{Funding}

The author(s) received no financial support for the research, authorship, and/or publication of this article.

\section{Notes}

1. Work-integrated learning (also known as 'work-based learning') refers to learning that is embedded in the experience of work (Gribble, Blackmore, \& Rahimi, 2015). In my course, students are placed in client organizations to work on real consulting projects over 10-weeks. Students are also required to attend workshops and lectures where they learn and practice various consulting skills and methodologies.

2. While problem-solving methodologies vary between consulting firms, they all subscribe to the basic principles of the scientific method (Liedtka, 2006). Other publicly accessible methodologies and resources, useful for teaching, are Paul Friga's (2009) TEAM FOCUS framework, as well as the chapters on structured problem diagnosis and structured solution development in Marc Baiij's (2014) book, 'An Introduction to Management Consultancy'.

3. Whilst the McKinsey methodology has not be officially disseminated through official publishing channels, the firm's methodology is widely known by consulting practitioners and those interested in consulting practice. McKinsey consultants frequently and openly share their problem-solving methodology with university students at career seminars and case competition workshops. A keyword search of ‘McKinsey’s 7-Step Problem Solving Approach' will return countless resources and diagrams on the McKinsey methodology. The 
PSC methodology has been developed based on publicly available practitioner resources related to the McKinsey approach.

4. The PSC is a fit-for-purpose methodology (i.e. a translation) and its purpose is to developmentally expose and teach students on structured problem solving approaches in consulting projects. The PSC has a pedagogical focus and does not seek to replicate the McKinsey approach. Thus, the PSC has deliberately omitted many techniques and tools (eg. SCQA framing, Minto pyramids, differential applications of structured problem solving to 'knowledge' and 'performance' gaps) that may be found in the McKinsey approach.

5. Unlike some other methodologies, the Problem Solving Cycle refers to tree branches as issues, rather than hypotheses. In the hypothesis-based approach, each branch needs to be phrased as another question or hypothesis statement; Liedtka (2006) provides some good technical guidance on this. In an issue-based approach, each branch is phrased as an issue statement or category label. I have found that the issue-based approach is more accessible and learnable for students. Further, the issue-based approach applies broadly, to all business problems, whereas the application of the hypothesis-based approach may be more restricted.

6. The following supplementary resources may be useful for instructors and students wanting to learn a broader range of techniques and approaches relevant to the synthesis stage: structure and tone of writing (see Bierck, 1998, 2002), pyramid principles (see Minto, 1999), and storyboarding (see Duarte, 2012). 


\section{References}

Baaij, M. G. (2014). An Introduction to Management Consultancy. Thousand Oaks, CA: Sage Publications.

Bierck, R. (1998). How to Structure What you Write. Harvard ID: C9812B-HCB-ENG. Boston, MA: Harvard Business School Publishing Corporation.

Bierck, R. (2002). Find the Right Tone for Your Business Writing. Harvard ID: C0109D-PDFENG. Boston, MA: Harvard Business School Publishing Corporation.

Block, P. (2011). Flawless Consulting. A Guide to Getting your Expertise Used. San Francisco, CA: Pfeiffer.

Duarte, N. (2012). HBR Guide to Persuasive Presentations. Boston, MA: Harvard Business Review Press.

Friga, P. N. (2009). The McKinsey Engagement: A powerful toolkit for more efficient and effective team problem solving. U.S.A: McGraw-Hill Professional.

Gribble, C., Blackmore, J., \& Rahimi, M. (2015). Challenges to providing work integrated learning to international business students at Australian universities. Higher Education, Skills and Work-Based Learning, 5(4), 401-416.

Hargadon, A. B., \& Bechky, B. A. (2006). When collections of creatives become creative collectives: A field study of problem solving at work. Organization Science, 17(4), 484-500.

Liedtka, J. M. (2006). Using Hypothesis-Driven Thinking in Strategy Consulting. Darden ID: UV0991. Charlottesville, VA: University of Virginia Darden School Foundation.

Minto, B. (2009). The Minto Pyramid Principle: Logic in Writing, Thinking, \& Problem Solving. Essex, UK: Pearson Education Limited 
Rasiel, E. M. \& Friga, P. N. (2001). The McKinsey Mind: Understanding and implementing the problem-solving tools and management techniques of the world's top strategic consulting firm. Chicago, United States: McGraw-Hill.

Rasiel, E. M. (1999). The McKinsey Way: Using the Techniques of the World's Top Strategic Consultants to Help You and Your Business. NY, United States: McGraw-Hill.

Schein, E. H. (1997). The concept of "client" from a process consultation perspective: A guide for change agents. Journal of Organizational Change Management, 10(3), 202216. 


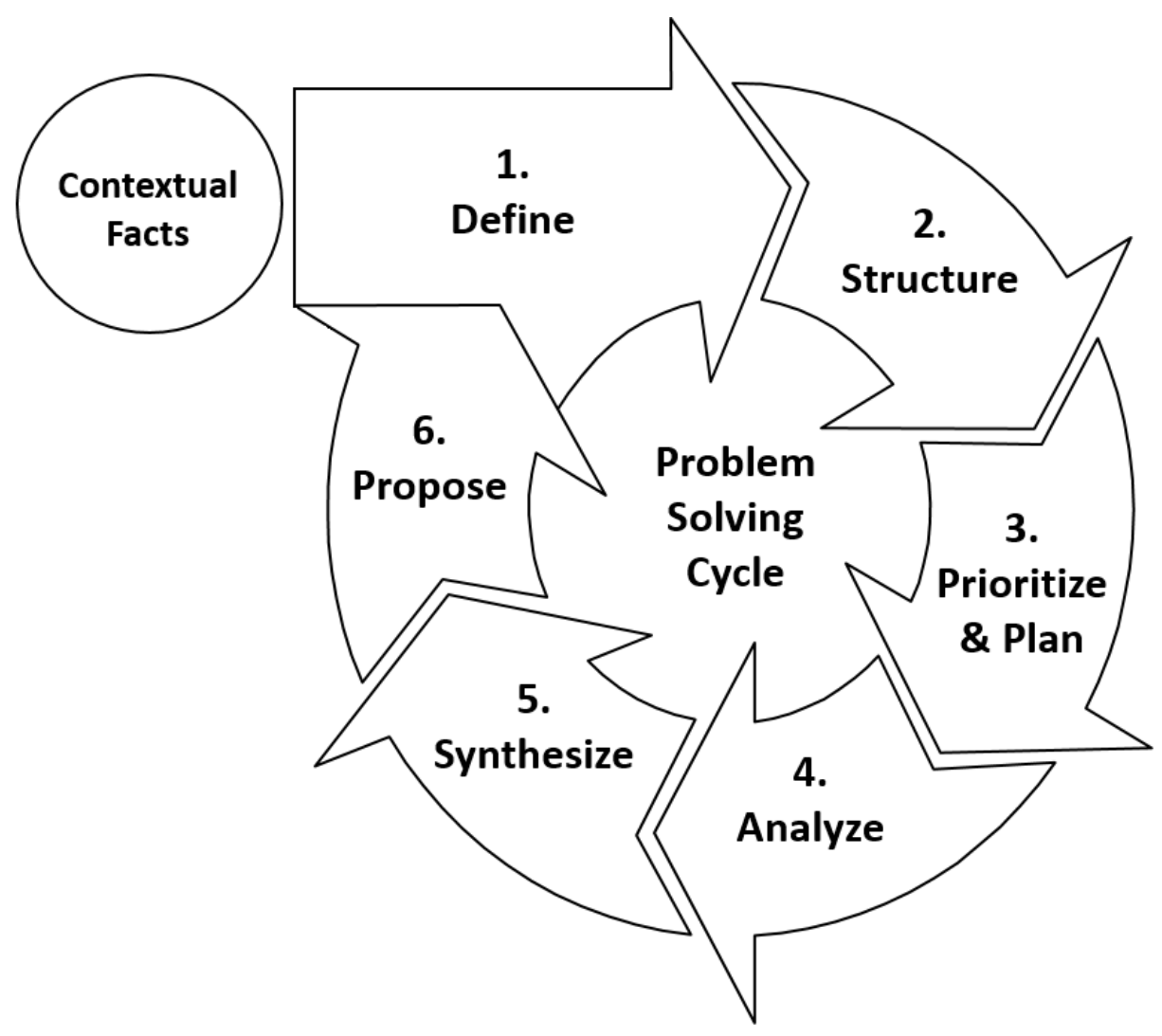

Figure 1. Problem solving cycle methodology 


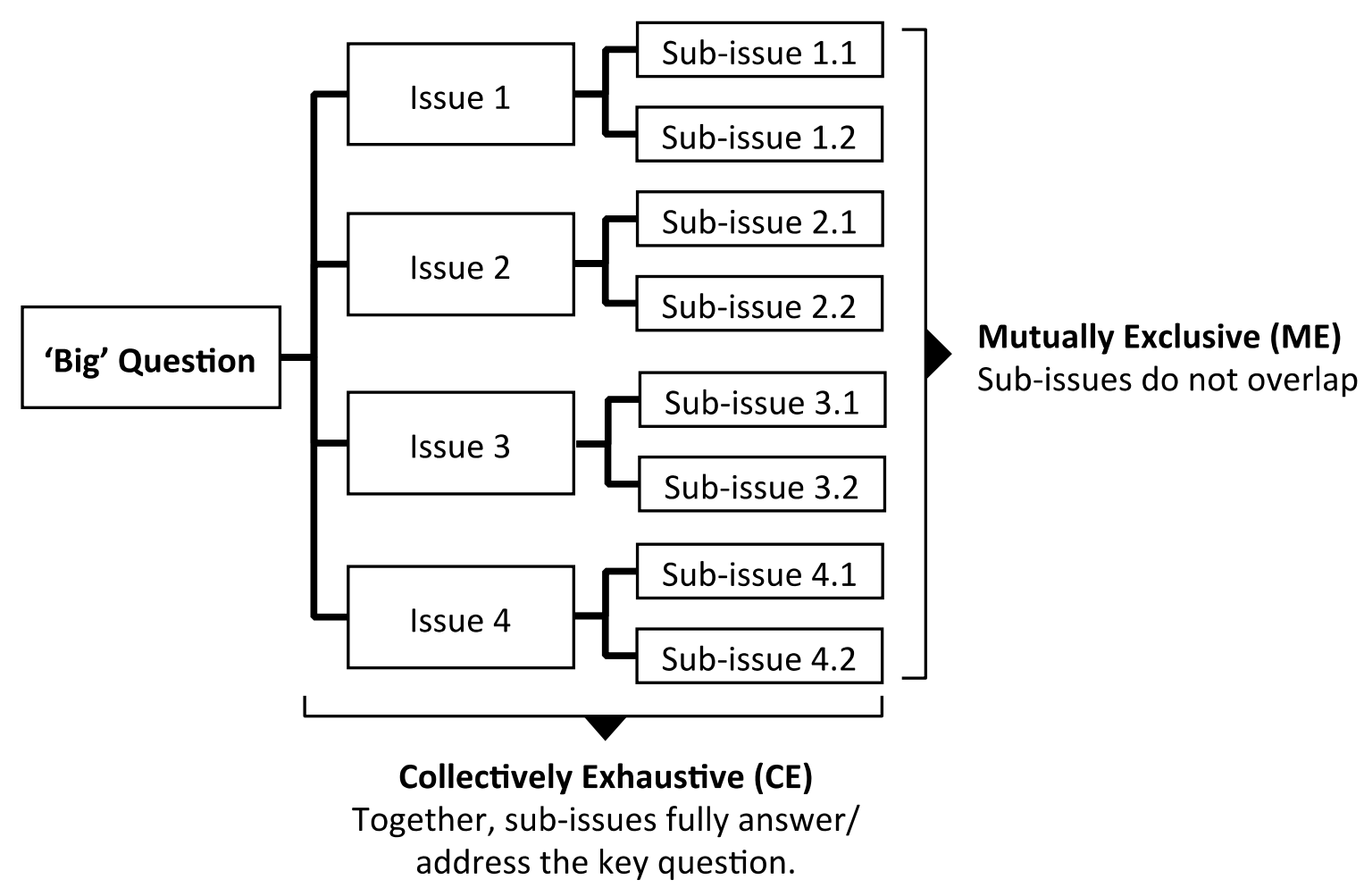

Figure 2. Structure of an issue tree 


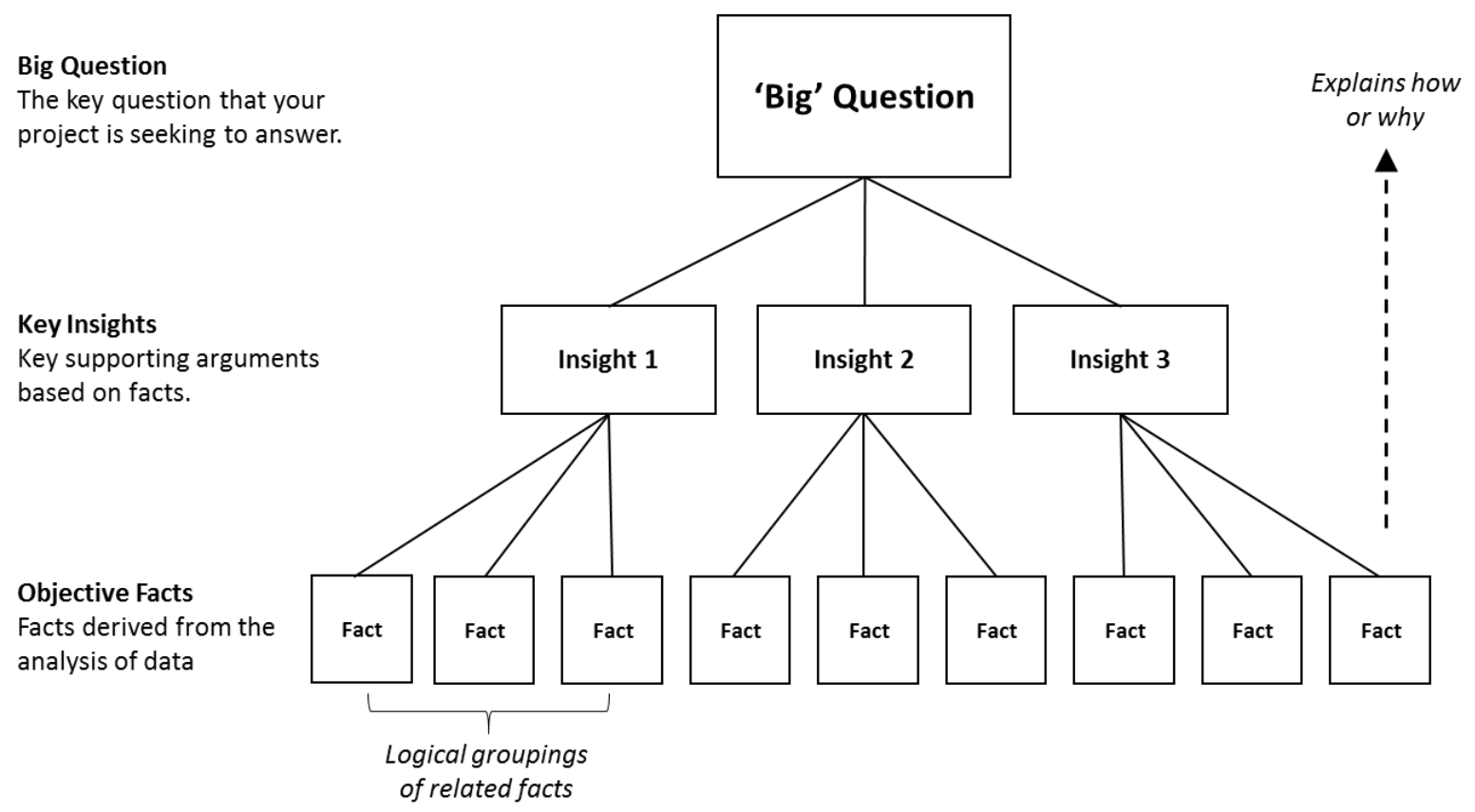

Figure 3. Synthesizing facts into insights 

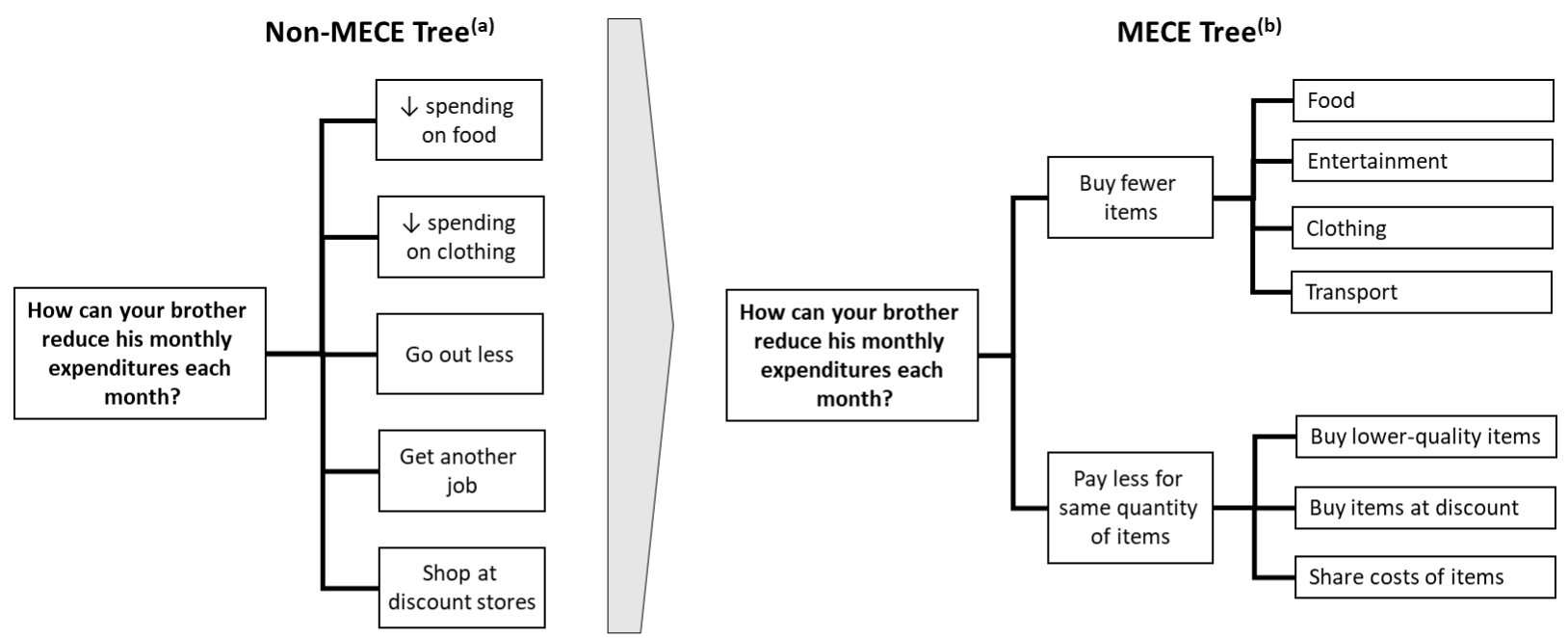

\section{Debriefing Notes}

(a) This is an example of a student's typical first attempt at decomposing an 'big question' into an issue tree. It breaches the MECE principle in three obvious ways: (1) 'Get another job' is irrelevant because it doesn't reduce expenditure, (2) 'Reduce spending on food and clothing' overlaps with 'Shop at discount shops' (i.e. not mutually exclusive), and (3) Many expenditure items have been omitted such as rent, utility bills, etc. (i.e. not collectively exhaustive)

(b) This is an example of an exemplar MECE tree. The determinants of monthly expense can be objectively formulated as: Expense $=$ Quantity $x$ Price. Using this logic, the tree can be broken into 'Buy fewer items' and 'Pay less for same quantity of items' which is both mutually exclusive and collectively exhaustive.

Figure B-1. Issue tree example - Reducing Personal Expenditure 


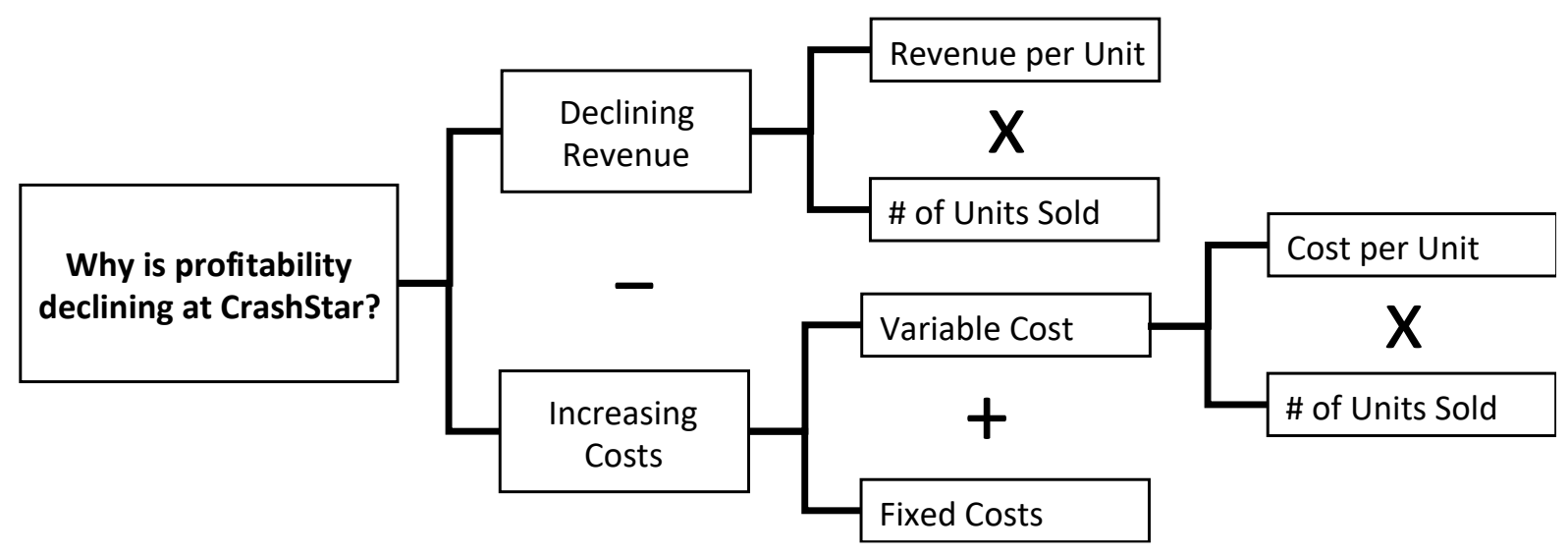

Figure B-2. Issue tree example - Profitability Problem 
Issue Tree

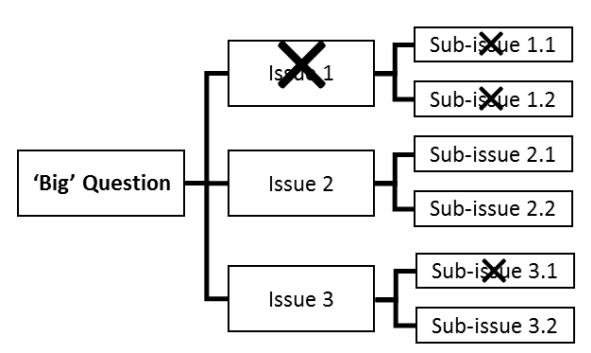

Note: The issue tree should be fully MECE prior to the prioritization stage. Issues that are eliminated as a result of prioritization should be crossed out. A data collection plan is then created for the remaining issues.
Data Collection Plan

\begin{tabular}{|l|l|l|l|}
\hline Ref & Issue / Sub-issue & Data Needs & Data Sources \\
\hline $\begin{array}{l}\text { Reference } \\
\text { number of issue }\end{array}$ & Name of issue & $\begin{array}{l}\text { What data required } \\
\text { to understand issue? }\end{array}$ & $\begin{array}{l}\text { Where will the data be } \\
\text { collected from? }\end{array}$ \\
\hline & & & \\
\hline & & & \\
\hline & & & \\
\hline & & & \\
\hline
\end{tabular}

Figure C-1. Creating a data collection plan 
Table 1. Format Translation Criterion

\begin{tabular}{lll}
\hline Translation & Criterion & Criterion Rationale \\
Criterion & Descriptor & \& PSC Examples \\
\hline Applicable & Can students easily learn and & When working on real client projects, \\
apply the methodology to their & students are already confronted with \\
client projects? & complexity and information overload. The \\
& class-based methodology needs to be easily \\
& recallable and implementable and shouldn't \\
& exceed students' cognitive load limits. \\
& $\begin{array}{l}\text { Example: The 7-stage McKinsey method } \\
\text { has been reduced into a 6-stage method. } \\
\text { Stage labels have also been simplified in the }\end{array}$ \\
& PSC to enhance the ease-of-recall of the \\
& various stages.
\end{tabular}

Comprehensible Are the terms and principles in Consulting methodologies use a lot of the methodology intuitive to jargon terms and profession-specific understand? phrasing. Many specific tools and frameworks are also embedded throughout practitioner methodologies. The class-based methodology should not be unnecessarily complex and should have a parsimonious focus on the process (not the tools) of 
problem-solving.

Example: Jargon terms in the McKinsey

method have been appropriated (e.g.

removal of 'Rapid Cycles') and various

tools (e.g. 5-whys, work breakdown

structures, risk management plans, FMEA)

have been stripped from the original

methodology when preparing the PSC.

Generalizable Can the methodology be applied to solve a non-context specific project problems?
The McKinsey methodology is most relevant to strategy projects. A class-based methodology needs to be generally applicable to all types of business problems (e.g. operational problems, thoughtleadership work). This is particularly important in work-integrated learning subjects where students could be assigned to work on non-strategy projects that span different functional areas.

Example: The PSC is less strategyorientated and has a stronger focus on general problem-solving. For instructors, strategy example problems should be 
balanced when general problems (see Figure

B-1) when teaching the PSC.

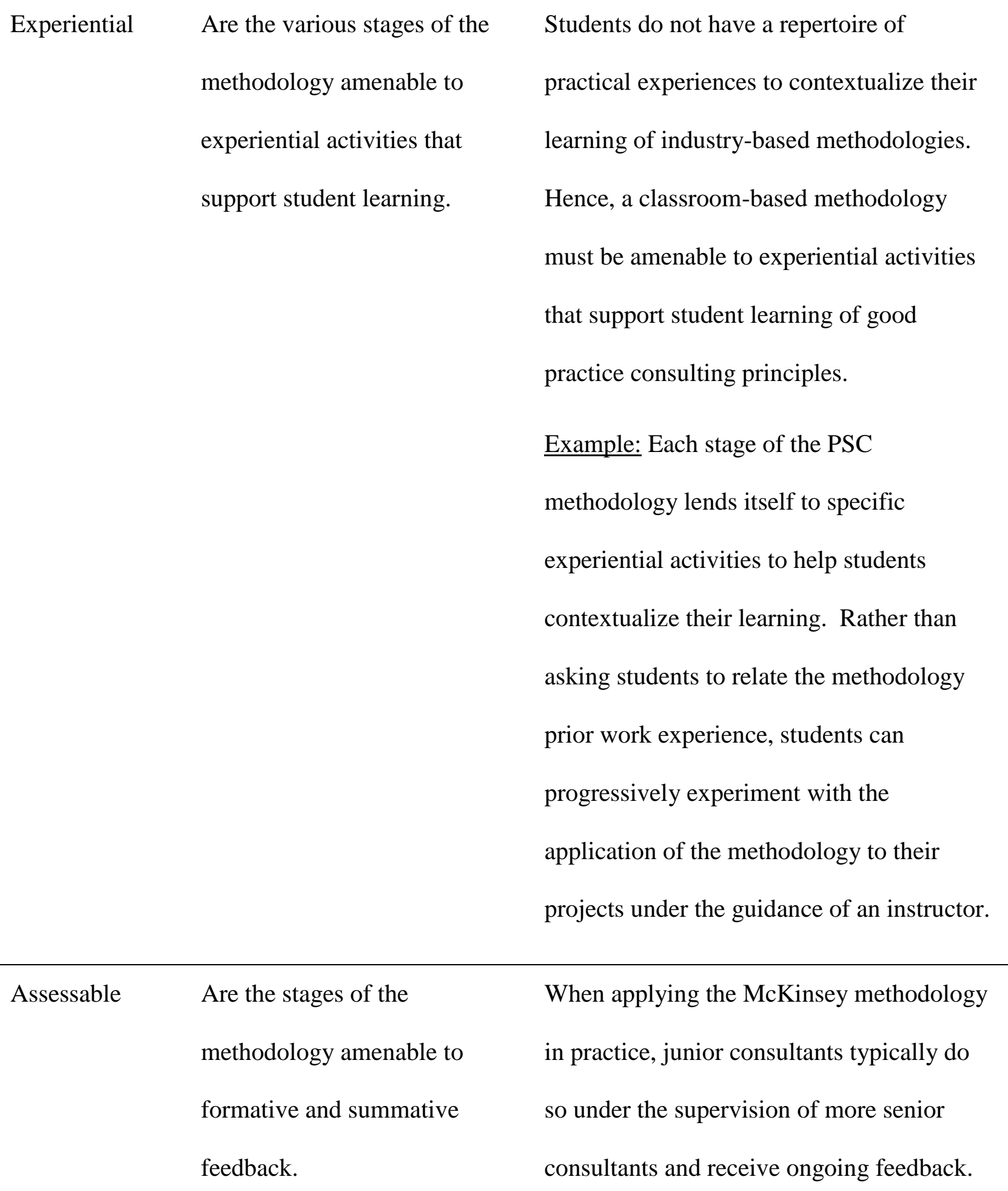


The classroom-based methodology needs to

preserve the feedback features of the

McKinsey approach.

Example: Each stage of the PSC

methodology can align with formative or

summative assessments depending the

learning objectives that an instructor has set

out for a subject. For instance, formative

and summative assessments can be used for

stages 1, 3 and 5 and 2, 4 and 6 respectively

(see Figure 1). 
Table D-1. Sample Consulting Projects and Analysis Used

\begin{tabular}{|c|c|c|c|c|}
\hline $\begin{array}{l}\text { Client } \\
\text { Profile }\end{array}$ & $\begin{array}{l}\text { Project } \\
\text { Aim }\end{array}$ & Sub-Issues & $\begin{array}{c}\text { Data } \\
\text { Sources }\end{array}$ & Analysis \\
\hline $\begin{array}{l}\text { Org } W \text { is a } \\
\text { not-for-profit } \\
\text { organization that } \\
\text { redistributes surplus } \\
\text { fresh food to } \\
\text { community programs } \\
\text { around Australia. }\end{array}$ & $\begin{array}{l}\text { Develop a business case } \\
\text { to create a subsidiary } \\
\text { social enterprise that } \\
\text { converts misshaped } \\
\text { fruit into juices sold via } \\
\text { juice trucks. }\end{array}$ & $\begin{array}{l}\text { Does Org } W \text { have the } \\
\text { capability to launch a } \\
\text { juice product and } \\
\text { compete? }\end{array}$ & $\begin{array}{l}\text { Internal stakeholder } \\
\text { interviews } \\
\text { Industry databases (e.g. } \\
\text { IBIS World, Company 360) } \\
\text { List of events that host food } \\
\text { trucks } \\
\text { Historical attendance } \\
\text { records }\end{array}$ & $\begin{array}{l}\text { SWOT analysis } \\
\text { Gap analysis of } \\
\text { capabilities }\end{array}$ \\
\hline $\begin{array}{l}\text { Company } X \text { is a global } \\
\text { animation studio that } \\
\text { has produced many } \\
\text { mainstream popular }\end{array}$ & $\begin{array}{l}\text { Develop 'go to market' } \\
\text { marketing initiatives to } \\
\text { build Company X's } \\
\text { brand affinity with }\end{array}$ & $\begin{array}{l}\text { How do Millennials } \\
\text { typically consume } \\
\text { entertainment? }\end{array}$ & $\begin{array}{l}\text { Trade publications } \\
\text { (e.g. McKinsey Quarterly) } \\
\text { Australian Bureau of } \\
\text { Statistics (ABS) }\end{array}$ & $\begin{array}{l}\text { Correlational analysis of } \\
\text { consumer preferences }\end{array}$ \\
\hline
\end{tabular}




\begin{tabular}{|c|c|c|c|c|}
\hline feature films. & Australian Millennials. & $\begin{array}{l}\text { What lifestyle factors } \\
\text { influence millennials } \\
\text { when purchasing } \\
\text { lifestyle brands? }\end{array}$ & $\begin{array}{l}\text { Focus groups } \\
\text { Surveys }\end{array}$ & $\begin{array}{l}\text { Thematic analysis of } \\
\text { qualitative responses } \\
\text { Psychographic analysis } \\
\text { (i.e. segmentation) }\end{array}$ \\
\hline $\begin{array}{l}\text { Bank } Y \text { is one of the } \\
\text { largest financial } \\
\text { institutions in } \\
\text { Australia and offers a } \\
\text { range of financial } \\
\text { products and services. }\end{array}$ & $\begin{array}{l}\text { Assess whether Bank } Y \\
\text { should expand its } \\
\text { offerings of self- } \\
\text { managed super fund } \\
\text { (SMSF) products in } \\
\text { Australia? }\end{array}$ & $\begin{array}{l}\text { What is the growth } \\
\text { trend of SMSF as } \\
\text { a proportion of the } \\
\text { overall superannuation } \\
\text { market? }\end{array}$ & $\begin{array}{l}\text { Government websites and } \\
\text { reports (e.g. Department of } \\
\text { Treasury and Finance) } \\
\text { News articles from the } \\
\text { financial press } \\
\text { Whitepapers from industry } \\
\text { bodies (e.g., Association of } \\
\text { Superannuation Funds of } \\
\text { Australia) }\end{array}$ & $\begin{array}{l}\text { Descriptive statistical } \\
\text { analysis and forecasting } \\
\text { of trends }\end{array}$ \\
\hline $\begin{array}{l}\text { Firm } Z \text { is one of the } \\
\text { world's largest }\end{array}$ & $\begin{array}{l}\text { Assess which industries } \\
\text { in Australia are likely to }\end{array}$ & $\begin{array}{l}\text { Which Australian } \\
\text { industries are subject to }\end{array}$ & $\begin{array}{l}\text { Regulatory information } \\
\text { from industry databases (i.e. }\end{array}$ & Five forces analysis \\
\hline
\end{tabular}




\begin{tabular}{|c|c|c|c|c|}
\hline $\begin{array}{l}\text { professional services } \\
\text { firms in the areas of } \\
\text { tax, audit, and } \\
\text { advisory. }\end{array}$ & $\begin{array}{l}\text { be positively or } \\
\text { negatively affected by } \\
\text { the sharing economy? }\end{array}$ & $\begin{array}{l}\text { prohibitive restrictions } \\
\text { on the exchange of } \\
\text { goods and services? }\end{array}$ & $\begin{array}{l}\text { IBIS World, MarketLine) } \\
\text { and Legal Information } \\
\text { Institutes (e.g., Australasian } \\
\text { Legal Information Institute) }\end{array}$ & Benchmarking \\
\hline & & $\begin{array}{l}\text { For identified } \\
\text { industries, to what } \\
\text { extent (a) is there an } \\
\text { economic inefficiency? } \\
\text { and (b) do users have } \\
\text { underutilized resources. }\end{array}$ & $\begin{array}{l}\text { Analyst reports by industry } \\
\text { think tanks (e.g., Deloitte } \\
\text { Access Economics, Grattan } \\
\text { Institute) } \\
\text { News sources (e.g., Factiva) }\end{array}$ & \\
\hline
\end{tabular}

